\title{
FAKTOR-FAKTOR YANG MEMENGARUHI SUSTAINABLE ENTREPRENEURSHIP PADA USAHA KECIL MENENGAH DI JAKARTA
}

\author{
Michael Kianto \\ Program Studi Magister Manajemen Universitas Tarumanagara \\ michael.kianto@ymail.com
}

\begin{abstract}
Entrepreneurship has both positive and negative contributions to our society. On the negative side, the degradation of environmental quality caused by entrepreneurial activities requires serious attention. As such, sustainable entrepreneurship has been suggested as an attempt to alleviate environmental problems. Furthermore, there are scant studies in regard to motivation and propensity in the development of sustainable entrepreneurs among SMEs practitioners. Thus, this study was conducted to address the factors associated with propensity for sustainable entrepreneurship among ownersmanagers of SMEs. This sample collection through purposive sampling. There are 100 respondents as sample of this research by using simple random sampling method. The data collection method conducted by questionnaire. Based on the descriptive analyses, this paper found that owners-managers of SMEs generally possessed positive or favorable attitude towards sustainability, concerned about social pressures on sustainability, perceived that sustainable entrepreneurship was attractive and perceived themselves as having sufficient ability for sustainable entrepreneurship.
\end{abstract}

Keyword: Sustainable Attitude, Social Norm, Perceived Desirability, Perceived Feasibility, Sustainable Entrepreneurship

\section{PENDAHULUAN}

Seiring cepatnya laju pembangunan, perekonomian Indonesia menghadapi beberapa masalah yang meliputi: penciptaan lapangan kerja, pemerataan pendapatan, pemberantasan kemiskinan, dan lemahnya daya saing industri dalam pasar global. Permasalahan ini semakin besar pengaruhnya, sedangkan kita dihadapkan pada kenyataan bahwa sumber daya alam Indonesia semakin berkurang.

Sehubungan dengan permasalahan di atas, pemerintah telah melakukan berbagai langkah kebijakan. Salah satu kebijakan yang penting dalam mengatasi masalah tersebut adalah dengan mencanangkan Gerakan Kewirausahaan Nasional (GKN) yang dimulai pada tanggal 2 Februai 2011. Warga Negara Indonesia dihimbau untuk meningkatkan semangat berwirausaha sejak awal dan bersungguh-sungguh sehingga terbentuk wirausaha-wirausaha yang memiliki sifat dinamis, kreatif, inovatif, pekerja keras, dan pantang menyerah. Wirausaha diharapkan merupakan seseorang yang percaya diri, mampu memanfaatkan sumber daya menjadi peluang, dan dengan kreativitasnya mampu mengubah sesuatu menjadi lebih bermanfaat sekaligus meningkatkan kesejahteraan diri, masyarakat, \& lingkungannya.

Wirausaha melalui usahanya, mampu menyerap tenaga kerja dan memberikan kesejahteraan kepada pekerja, pelanggan, distributor, masyarakat umum, dan pemerintah. Masyarakat memperoleh barang dan jasa dengan mudah dan karyawan memperoleh penghasilan dari kegiatan produksi dan manajemen perusahaan.

Apabila Indonesia mampu melahirkan wirausaha tangguh dan bukan pengusaha yang besar karena fasilitas, kolusi, dan korupsi maka sebagian besar permasalahan ekonomi dan sosial politik dapat diatasi. Dengan adanya pengusaha yang tangguh dalam pasar yang sehat 
akan menciptakan nilai tambah yang tinggi terhadap produk baik barang maupun jasa, meningkatkan daya saing, meningkatkan pertumbuhan dan kemandirian ekonomi nasional, meningkatkan produktifitas, serta menciptakan efisiensi sumber daya alam.

Berdasarkan penelitian oleh Cohen \& Winn (2007), menyatakan bahwa Kewirausahaan telah memberikan kontribusi besar terhadap pembangunan ekonomi dan nonekonomi suatu bangsa. Wirausaha menciptakan lapangan kerja, meningkatkan produk, membuat bisnis baru, perubahan kehidupan masyarakat, dll. Namun, kegiatan kewirausahaan juga telah menyebabkan efek yang negatif, yang mengakibatkan menurunnya kualitas lingkungan. Berbagai masalah lingkungan, seperti pemanasan global dan pemakaian sumber daya alam yang terbatas/lama untuk diperbaharui.

Sejak kegiatan kewirausahaan dianggap sebagai penyebab kerusakan lingkungan, pengusaha harus berperan dalam mengelola isu-isu keberlanjutan (Hockerts \& Wüstenhagen, 2010; O'Neil \& Ucbasaran, 2011; Parrish, 2010; Tilley \& Young, 2009). Upaya menghubungkan kewirausahaan dengan manajemen berkelanjutan telah mengembangkan metode baru yang disebut "Sustainable Entrepreneurship" (Den \& McMullen, 2007). Meskipun sustainable entrepreneurship telah dipopulerkan selama bertahun-tahun, sustainable entrepreneurship masih menerima penerimaan yang rendah dari praktisi bisnis kecil dan menengah.

Informasi dalam hal ini untuk menjalankan praktek-praktek sustainable entrepreneurship di kalangan usaha kecil dan menengah (UKM) masih jarang. Omar dan Samuel (2011) menegaskan, UKM yang memikirkan pada pengelolaan lingkungan masih kurang dibandingkan perusahaan besar.

Tidak diragukan lagi, keterlibatan UKM dalam pengelolaan berkelanjutan memerlukan keputusan positif dari pemilik-manajer atau pengambil keputusan utama dari UKM. Sejak proses pengambilan keputusan terkait dengan proses kognitif, sehingga itu menjadi penting untuk memahami bagaimana aspek kognitif memengaruhi keputusan. Secara khusus, tidak banyak yang telah dipelajari dalam hal motivasi dan kecenderungan dalam pengembangan usaha berkelanjutan. Kurangnya pengetahuan tentang faktor-faktor yang berhubungan dengan perilaku sustainable entrepreneurship dapat menyebabkan perencanaan yang buruk dan pemborosan sumber daya dalam pengembangan sustainable entrepreneurship.

Kewirausahaan telah dianggap sebagai penyumbang penting bagi pertumbuhan dan perkembangan ekonomi dan non ekonomi suatu negara (Fayolle, 2007). Baru-baru ini, ada konsep baru yang dikenal sebagai "sustainable entrepreneurship" yang menghubungkan pembangunan berkelanjutan dengan kewirausahaan (Schaltegger \& Wagner, 2008). Selama bertahun-tahun, berbagai peneliti menggunakan istilah ini secara bergantian dengan istilah lain seperti "ecopreneurship" (Gerlach, 2003), "environmental entrepreneurship" (Dixon \& Clifford, 2007; Krueger, 2005; Schlange, 2006) atau "green entrepreneurship" Chick, 2009). Berdasarkan Majid dan Koe (2012: 300), penelitian ini menganggap sustainable entrepreneurship sebagai "sebuah proses di mana pengusaha memanfaatkan peluang secara inovatif untuk keuntungan ekonomi, keadilan masyarakat, kualitas lingkungan dan pelestarian budaya."

Berdasarkan latar belakang yang telah dikemukakan di atas, penulis tertarik untuk meneliti dengan judul "Faktor-Faktor yang Memengaruhi Sustainable Entrepreneurship pada Usaha Kecil Menengah di Jakarta."

\section{LANDASAN TEORI}

\section{Sustainable Attitude}

Menurut Sholiat (2013) Sustainability adalah kemampuan suatu sistem untuk mempertahankan tingkat produksinya yang dibentuk oleh alam dalam kurun waktu jangka panjang. 
Sikap (attitude) didefinisikan oleh Robbins (2007) sebagai pernyataan evaluatif, baik yang menyenangkan maupun tidak menyenangkan terhadap objek, individu, atau peristiwa. Hal ini mencerminkan bagaimana perasaan seseorang tentang sesuatu. Sementara Kreitner dan Kinicki (2005) mendefinisikan sikap (attitude) sebagai kecenderungan merespon sesuatu secara konsisten untuk mendukung atau tidak mendukung dengan memperhatikan objek tertentu.

Menurut Do Paco et al (2009) Attitude adalah: "Individuals who possess intention towards a behavior would demonstrate a favorable evaluation or simply known as "positive attitude" on that particular behavior (Ajzen, 1991). In other words, it can be said that attitude influences a person's intention towards behaving in certain manners. In many extant literatures, attitude has been found as important factor of entrepreneurial intention."

Menurut Schick et al (2005) Sustainability adalah: "It was also an important determinant of exercising sustainability practices in businesses." Menurut Tonglet et al (2004) Sustainable Attitude adalah: "In regards to environmental practices, sustainability attitude was also considered as a main predictor of pro-environment intention."

Menurut beberapa definisi di atas, Sustainable Attitude adalah suatu sikap yang menunjukan ketertarikan yang signifikan terhadap keberadaan kelangsungan lingkungan.

\section{Social Norm}

Menurut AA. Nurdiaman (2009) Norm adalah suatu bentuk tatanan hidup yang berisikan aturan-aturan dalam bergaul di masyarakat.

Menurut Sarjono Soekanto (1989) norma adalah aturan yang berlaku di dalam masyarakat yang disertai dengan sanksi bagi individu atau kelompok bila melanggar aturan tersebut. Sanksi bisa berupa teguran, denda, pengucilan, atau hukuman fisik. Pengertian norma sosial oleh Soerjono Soekanto diatas mengatakan bahwa dalam masyarakat akan tercipta aturan aturan yang akan mengikat individu individu didalamnya. Selain itu, setiap individu tidak akan memiliki pilihan selain mematuhi norma tersebut atau mengalami sanksi. Sedangkan menurut John Macionis (1991) norma adalah segala aturan dan harapan masyarakat yang memandu segala perilaku anggota masyarat. Menurut Isworo, Hadi, dan Wiyono (2007) norma adalah sebuah bentuk peraturan/petunjuk hidup (way of life) yang memberikan pembeda antara baik untuk dilaksanakan dan perbuatan yang buruk yang harusnya dihindari sehingga tercapai tujuan masyarakat untuk mewujudkan ketertiban. Menurut Winandi (dalam Ibrahim, 2003) sosial adalah segala sesuatu yang berkenaan dengan masyarakat yang lahir, tumbuh, dan berkembang dalam kehidupan bersama. Azjen (1991) menegaskan, norma sosial akan melakukan atau tidak melakukan suatu perilaku tertentu. Moriano et al menemukan norma sosial secara signifikan berhubungan dengan niat kewirausahaan. Vermeir et al (2008) mengatakan bahwa tujuan terhadap perilaku berkelanjutan dipengaruhi oleh tekanan sosial seperti pendapat dari individu atau pihak lainnya. Selain itu menurut Birgelen et al (2009) norma sosial dan niat perilaku ekologi juga berpengaruh signifikan terkait satu sama lain. Pacheco et al (2010) mengatakan bahwa norma sosial sangat penting dalam memengaruhi lingkungan dari tindakan kewirausahaan seseorang.

Dari beberapa definisi di atas, dapat disimpulkan norma sosial adalah kebiasaan umum yang menjadi patokan perilaku dalam suatu kelompok masyarakat dan batasan wilayah tertentu. Norma akan berkembang seiring dengan kesepakatan-kesepakatan sosial masyarakatnya, sering juga disebut dengan peraturan sosial.

\section{Perceived Desirability}

Menurut Slameto (2010:102) persepsi adalah proses yang menyangkut masuknya pesan atau informasi kedalam otak manusia, melalui persepsi manusia terus-menerus 
mengadakan hubungan dengan lingkungannya. Hubungan ini dilakukan lewat inderanya, yaitu indera penglihatan, pendengaran, peraba, perasa, dan penciuman.

Menurut Robbins (2003:97) yang mendeskripsikan bahwa persepsi merupakan kesan yang diperoleh oleh individu melalui panca indera kemudian di analisa (diorganisir), diintepretasi dan kemudian dievaluasi, sehingga individu tersebut memperoleh makna. Menurut Purwodarminto (1990: 759), persepsi adalah tanggapan langsung dari suatu serapan atau proses seseorang mengetahui beberapa hal melalui pengindraan. Persepsi mempunyai sifat subjektif, karena bergantung pada kemampuan dan keadaan dari masing-masing individu, sehingga akan ditafsirkan berbeda oleh individu yang satu dengan yang lain. Dengan demikian persepsi merupakan proses perlakuan individu yaitu pemberian tanggapan, arti, gambaran, atau penginterprestasian terhadap apa yang dilihat, didengar, atau dirasakan oleh indranya dalam bentuk sikap, pendapat, dan tingkah laku atau disebut sebagai perilaku individu.

Minat/keinginan erat hubungannya dengan perhatian yang dimiliki. Karena perhatian mengarahkan timbulnya kehendak pada seseorang. Kehendak atau kemauan ini juga erat hubungannya dengan kondisi fisik seseorang misalnya dalam keadaan sakit, capai, lesu atau mungkin sebaliknya yakni sehat dan segar. Juga erat hubungannya dengan kondisi psikis seperti senang, tidak senang, tegang, bergairah dan seterusnya (Sobur, 2003:246). Menurut Crow et al (1993) keinginan adalah sesuatu yang berhubungan dengan daya gerak yang mendorong kita cenderung atau merasa tertarik pada orang, benda, kegiatan ataupun bisa berupa pengalaman yang efektif yang dirangsang oleh kegiatan itu sendiri. Rast et al (2004) menyatakan bahwa dalam minat itu terdapat hal-hal pokok diantaranya: (1) adanya perasaan senang dalam diri yang memberikan perhatian pada objek tertentu, (2) adanya ketertarikan terhadap objek tertentu, (3) adanya aktivitas atas objek tertentu, (4) adanya kecenderungan berusaha lebih aktif, (5) objek atau aktivitas tersebut dipandang fungsional dalam kehidupan dan (6) kecenderungan bersifat mengarahkan dan mempengaruhi tingkah laku individu. Definisi keinginan menurut Shaleh (2004:262) adalah suatu kecenderungan untuk memberikan perhatian dan bertindak terhadap orang, aktivitas atau situasi yang menjadi objek dari minat tersebut dengan disertai perasaan senang.

Dari beberapa definisi di atas, dapat disimpulkan bahwa keinginan merupakan kecenderungan atau arah keinginan terhadap sesuatu untuk memenuhi dorongan hati, keinginan merupakan dorongan dari dalam diri yang mempengaruhi gerak dan kehendak terhadap sesuatu, merupakan dorongan kuat bagi seseorang untuk melakukan segala sesuatu dalam mewujudkan pencapaian tujuan dan cita-cita yang menjadi keinginannya.

\section{Perceived Feasibility}

Menurut Victor C. X. Wang (2014), perceived feasibility adalah Sejauh mana seseorang percaya bahwa mereka memiliki sumber daya yang dibutuhkan (atau keterampilan) untuk berhasil melaksanakan tugas tersebut.

Perceived feasibility menunjukkan derajat kepercayaan dimana seseorang memandang dirinya mempunyai kemampuan untuk mengumpulkan sumberdaya-sumberdaya (manusia, sosial, finansial) untuk membangun usaha baru (Segal, et al.,2005)

Perceived feasibility is defined as the degree to which people consider themselves personally able to carry out that behaviour. The presence of role models, mentors or partners would be a decisive element in establishing the individual's feasibility level. In turn, both types of perceptions are determined by cultural and social factorsthrough their influence on the individual's value system (Shapero \& Sokol, 1982).

Perceived Feasibility didefinisikan sebagai tingkat di mana memulai bisnis baru dianggap sebagai pilihan karir yang layak (Sarah Drakopoulou Dodd, 2011) 


\section{Sustainable Entrepreneurship}

Menurut Schaltegger dan Wagner (2011), "Current definition for sustainable entrepreneurship focus on new solutions or sustainable innovations that aim at the mass market and provide value to society. entrepreneurs or individuals or companies that are sustainability driven within their core business and contribute towards a sustainable development can be called sustainable entrepreneurs.“

Menurut Porter dan Kramer (2011), "Sustainable entrepreneurship stand for a unique concept of sustainable business strategies that focuses on increasing social as well as business value - shared value - at the same time."

Menurut Abrahamsson (2007), "Sustainable entrpreneurship is a business model with a cause which aims to solve problems related to the sustainability agenda and also to create social and environmental sustainability.“

Ada 3 poin penting menurut Abrahamsson (2007) dalam Sustainable Entrepreneurship:

1. Sustainable Entrepreneurship menemukan dan membuat inovasi untuk memecahkan masalah yang berkaitan dengan masalah keberlanjutan.

2. Sustainable Entrepreneurship berarti untuk mendapatkan solusi ke pasar melalui pengorganisasian yang kreatif

3. Sustainable Entrepreneurship dalam proses menambah nilai keberlanjutan dengan melihat sistem pendukung kehidupan.

Dengan demikian, Sustainable Entrepreneurship adalah kegiatan membangun dan menjalankan bisnis dengan memperhatikan lingkungan dan keberlanjutan sumber daya yang ada untuk digunakan baik untuk masa kini maupun di masa depan.

\section{METODE PENELITIAN}

Jenis penelitian ini adalah penelitian kuantitatif. Sumber data dalam penelitian ini adalah data primer yang merupakan hasil kuesioner dari usaha kecil menengah (UKM) di Jakarta. Metode pengumpulan data yang digunakan dalam penelitian ini adalah dengan menggunakan kuesioner. Metode analisis data menggunakan regresi ganda.

\section{HASIL ANALISIS DATA}

\section{Tabel 1}

Uji Validitas dan Reliabilitas

Sustainable Attitude

\begin{tabular}{|c|c|c|c|}
\hline Variabel & Indikator & $\begin{array}{c}\text { Corrected- } \\
\text { item total } \\
\text { correlation }\end{array}$ & Keterangan \\
\hline \multirow{4}{*}{$\begin{array}{c}\text { Sustainable } \\
\text { Attitude }\end{array}$} & Sustainable Attitude 1 &, 640 & Valid \\
\cline { 2 - 4 } & Sustainable Attitude 2 &, 645 & Valid \\
\cline { 2 - 4 } & Sustainable Attitude 3 &, 656 & Valid \\
\cline { 2 - 4 } & Sustainable Attitude 4 &, 633 & Valid \\
\cline { 2 - 4 } & Sustainable Attitude 5 &, 686 & Valid \\
\hline
\end{tabular}


Tabel 2

Social Norm

\begin{tabular}{|c|l|c|c|}
\hline Variabel & \multicolumn{1}{|c|}{ Indikator } & $\begin{array}{c}\text { Corrected- } \\
\text { Item total } \\
\text { correlation }\end{array}$ & Keterangan \\
\hline \multirow{3}{*}{ Social Norm } & Social Norm 1 &, 537 & Valid \\
\cline { 2 - 4 } & Social Norm 2 &, 416 & Valid \\
\cline { 2 - 4 } & Social Norm 3 &, 840 & Valid \\
\cline { 2 - 4 } & Social Norm 4 &, 840 & Valid \\
\cline { 2 - 4 } & Social Norm 5 &, 720 & Valid \\
\hline
\end{tabular}

Table 3

Perceeived Desirability

\begin{tabular}{|c|l|c|c|}
\hline Variabel & \multicolumn{1}{|c|}{ Indikator } & $\begin{array}{c}\text { Corrected- } \\
\text { item total } \\
\text { correlation }\end{array}$ & Keterangan \\
\hline \multirow{2}{*}{$\begin{array}{c}\text { Perceived } \\
\text { Desirability }\end{array}$} & $\begin{array}{l}\text { Perceived } \\
\text { Desirability } 1\end{array}$ &, 841 & Valid \\
\cline { 2 - 4 } & $\begin{array}{l}\text { Perceived } \\
\text { Desirability } 2\end{array}$ &, 808 & Valid \\
\cline { 2 - 4 } & $\begin{array}{l}\text { Perceived } \\
\text { Desirability 3 }\end{array}$ &, 759 & Valid \\
\cline { 2 - 4 } & $\begin{array}{l}\text { Perceived } \\
\text { Desirability 4 }\end{array}$ &, 525 & Valid \\
\hline
\end{tabular}


Perceived Feasibillity

Table 4

\begin{tabular}{|c|l|c|c|}
\hline Variabel & Indikator & $\begin{array}{c}\text { Corrected- } \\
\text { item total } \\
\text { correlation }\end{array}$ & Keterangan \\
\hline \multirow{3}{*}{$\begin{array}{c}\text { Perceived } \\
\text { Feasibility }\end{array}$} & Perceived Feasibility 1 &, 906 & Valid \\
\cline { 2 - 4 } & Perceived Feasibility 2 &, 883 & Valid \\
\cline { 2 - 4 } & Perceived Feasibility 3 &, 832 & Valid \\
\cline { 2 - 4 } & Perceived Feasibility 4 &, 910 & Valid \\
\cline { 2 - 4 } & Perceived Feasibility 5 &, 835 & Valid \\
\hline
\end{tabular}

Sustainable Entrepreneurship

Tabel 5

\begin{tabular}{|c|c|c|c|}
\hline \multirow{2}{*}{ Variabel } & Indikator & $\begin{array}{c}\text { Corrected- } \\
\text { Item total } \\
\text { correlation }\end{array}$ & $\begin{array}{c}\text { Keterang } \\
\text { an }\end{array}$ \\
\hline \multirow{4}{*}{$\begin{array}{c}\text { Sustainable } \\
\text { Entrepreneurship }\end{array}$} & $\begin{array}{c}\text { Sustainable Entrepreneurship } \\
1\end{array}$ &, 238 & Valid \\
\cline { 2 - 4 } & $\begin{array}{c}\text { Sustainable Entrepreneurship } \\
2\end{array}$ &, 773 & Valid \\
\cline { 2 - 4 } & $\begin{array}{c}\text { Sustainable Entrepreneurship } \\
3\end{array}$ &, 791 & Valid \\
\cline { 2 - 4 } & $\begin{array}{c}\text { Sustainable Entrepreneurship } \\
4\end{array}$ &, 802 & Valid \\
\hline
\end{tabular}

Table 6

Uji Reliabilitas

\begin{tabular}{|c|c|c|}
\hline Variabel & Cronbach Alpha & Keterangan \\
\hline Sustainable Attitude &, 660 & Reliabel \\
\hline Social Norm &, 692 & Reliabel \\
\hline $\begin{array}{c}\text { Perceived } \\
\text { Desirability }\end{array}$ &, 722 & Reliabel \\
\hline Perceived Feasibility &, 920 & Reliabel \\
\hline $\begin{array}{c}\text { Sustainable } \\
\text { Entrepreneurship }\end{array}$ &, 601 & Reliabel \\
\hline
\end{tabular}

Tabel 7

Hasil Regresi

\begin{tabular}{|c|c|c|c|}
\hline Variabel & $\mathrm{B}$ & $\mathrm{t}$ & Sig. \\
\hline Sustainable Attitude &, 050 &, 438 &, 662 \\
\hline Social Norm &,- 0.54 &,- 585 &, 560 \\
\hline Perceived Desirability &, 017 &, 127 &, 900 \\
\hline Perceived Feasibility &, 120 & 1,664 & 0,99 \\
\hline F & \multicolumn{3}{|c|}{} \\
\hline $\mathrm{R}^{2}$ &, 050 & \\
\hline
\end{tabular}


Berdasarkan hasil analisis yang disajikan pada Tabel 1, didapat nilai sig sebesar 0,662 untuk pengaruh sustainable attitude terhadap sustainable attitude yang artinya sig $>0,05$. Oleh karena itu tidak terdapat pengaruh yang signifikan sustainable attitude terhadap sustainable entrepreneurship. Berdasarkan hasil analisis yang disajikan pada Tabel 1, didapat nilai sig sebesar 0,560 untuk pengaruh social norm terhadap sustainable entrepreneurship yang artinya sig $>0,05$. Oleh karena itu tidak terdapat pengaruh yang signifikan social norm terhadap sustainable entrepreneurship. Berdasarkan hasil analisis yang disajikan pada Tabel 1, didapat nilai sig sebesar 0,900 untuk pengaruh perceived desirability terhadap sustainable entrepreneurship yang artinya sig $>0,05$. Oleh karena itu tidak terdapat pengaruh signifikan perceived desirability terhadap sustainable entrepreneurship. Berdasarkan hasil analisis yang disajikan pada Tabel 1, didapat nilai sig sebesar 0,99 untuk pengaruh perceived feasibility terhadap sustainable entrepreneurship yang artinya sig $>0,05$. Oleh karena itu tidak terdapat pengaruh signifikan perceived feasibility terhadap sustainable entrepreneurship

Berdasarkan Tabel 1 besarnya koefisien determinasi berdasarkan $\mathrm{R}$ square adalah 0,50 artinya sebesar 50\% variasi sustainable entrepreneurship dapat dijelaskan oleh variabel sustainable attitude, social norm, perceived desirability, dan perceived feasibility. Sisanya dijelaskan oleh variabel lain.

\section{KESIMPULAN}

Berdasarkan penelitian dan pembahasan yang telah dijelaskan pada analisis data maka dapat diambil beberapa kesimpulan sebagai berikut:

1. Tidak terdapat pengaruh signifikan sustainable attitude terhadap sustainable entrepreneurship.

2. Tidak terdapat pengaruh signifikan social norm terhadap sustainable entrepreneurship.

3. Tidak terdapat pengaruh signifikan perceived desirability terhadap sustainable entrepreneurship

4. Tidak terdapat pengaruh signifikan perceived feasibility terhadap sustainable entrepreneurship.

\section{SARAN}

Terkait dengan hasil penelitian ini, terdapat beberapa saran yang sekiranya dapat bermanfaat untuk perusahaan dan untuk penelitian selanjutnya, yaitu sebagai berikut:

1. Diharapkan pada penelitian selanjutnya menambah variabel baru, sehingga dengan adanya jumlah variabel baru yang dimasukkan akan membuat tema baru yang lebih menarik dan bermanfaat untuk kepentingan pengembangan ilmu pengetahuan.

2. Diharapkan pada penelitian selanjutnya disarankan untuk meneliti lebih banyak lagi UKM di daerah lain di luar Jakarta Barat agar dapat mengetahui lebih luas lagi mengenai factor-faktor yang mempengaruhi wirausaha berkelanjutan dalam usaha kecil dan menengah (UKM).

3. Peneliti menyarankan bahwa para wirausaha harus lebih memperhatikan lingkungan dalam menjalankan bisnisnya.

4. Dalam mengumpulkan data tidak hanya menggunakan kuesioner, namun menggunakan metode lainnya seperti wawancara atau mengobservasi tanpa diketahui oleh individu itu sendiri agar mengurangi bias. 


\section{DAFTAR PUSTAKA}

Az Nurdiaman. 2009. Kecakapan. Berbangsa dan Berwarganezaraan Pendidikan Kewarganegaraan. Jakarta: Busat Rerbukuan Depdilonas.

Abrahamsson, A. Sustainopreneurship-Business with a Cause: Conceptualizing Entrepreneurship for Sustainability. Master Thesis in Business Administration, Saxiö University School of Management and Economics, Sxceeden.

Ajzen. I., 1991. The Theory of Planned Behaxiour. In: Organizational Behariour and Human Decision Process. Amherst, MA: Elgevier, 50: 179-211.

Birgelen, M.V., Semeïn, J., \& Keicher, M. (2009). Packaging and Proenxironmental Consumption Behavior: Investigating Purchase and Disposal Decisions for Beverages. Environment and Behavior,4l(1), 125-146.

Cohen, B., \& Wimn, M.I. (2007). Market Imperfections, Opportunity and Sustainable Entrepreneruship. Journal of Business Venturing, 22(1), 29-49.

Crow et al. 1993. Starters as Finisher: Starters Properties Relevant to Cheese Ripening. Int Dairy J. 3423 - 460

Dean, T.J., \& McMullen, J.S. (2007). Toward a Theory of Sustainable Entrepreneurship: Reducing Environmental Degradation through Entrepreneurial Action. Journal of Business Venturing, 22(1), 50-76.

Hockerts, K., \& Wlistenhagen, R (2010). Greening Goliaths Versus Emerging Daxide: Theorizing about The Role of Incumbents andNew Entrants in Sustainable Entrepreneurship. Journal of Business Venturing, 25(5), 481-492.

Ibrahim Xacob, H. M. Studi Kelayakan Bisnis, Edisi Rexiai, Penerbit PT. Rineka Sipata, Jakarta, 2003.

Iswors, Hadi, dan Wlyome 2007. Kevarganegaraan untuk SMP Kelas VIII. Jakarta: Ganecca Exact.

Kreitner, Robert dan Kinicki, Angelo. 2005. Rerilaks Qxganisasi, bukn 1 dan 2, Jabarta. :Salemba Empat.

Macionis, John J. 1991. Sociology. Hertfordshire, U.K. . Prentice Hall
Nana Sudjanan, Dr dan IbrahimDr, MA, Renelitian dan Penilaian Pendidikan, Sinar Baru Algensindo, Bandung, 2004.

Porter, M. E., \& Kramer, M. R. (JanuariEebruari 2011). Creating Shared Value. Harvard Business Review 3-17.

Purwodarminto. 1990. Kamus Umum Bahasa Indonesia. Jakarta: Balai Pustaka.

Schaltegger, S. and Wagner, M. (2011) "Sustainable Entrepreneurship and SustainabiliteInnovation: Categories and Interactions ${ }^{\text {"f }}$, Business Strategy and the Environment, Vol. 20, No. 4, pp.222-237.

Shaleh, Abdul Rahman \& Wabah, Mubbik Abdul. 2004. Psikelogi Suaty Pengantar Dalam Rerafektifislam. Jakarta: Kencana

Shapero, A. \& Sokold. (1982). The Social Dimention of Entrepreneurship. In Kent,C.A.,Sexton.DL. \& Vesper.K.H (Eds.). The Encyclopedia of Entrepreneurship. Engelwood CliftsII. Prentice-Hall

Slamento. (2010). Belajar dan Eabtor-Eaktor yang Mempengaruhinya. Jakarta: Rineka Cipta

Tonglet, M, Philips, P.S., \& Read, A.D. (2004). Using the Theory of Planned Bebaxiour to Investigate the Determinants of Recycling Behavior: A Case Study from Brixworth, UK. Resources, Conservation and Recycling, 41, 191-214.

http://www.htwchur.ch/uploads/media/ABE AI_06_Schlange_01.pdf 


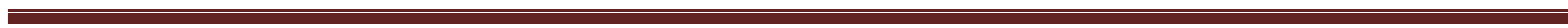
$\cdot$ 